\title{
Study Day of Disease Response
}

National Cancer Institute

\section{Source}

National Cancer Institute. Study Day of Disease Response. NCI Thesaurus. Code

C117390.

The study day that a disease response assessment is performed. 